\title{
Onset Coding Is Degraded in Auditory Nerve Fibers from Mutant Mice Lacking Synaptic Ribbons
}

\author{
Bradley N. Buran, ${ }^{1,2}$ Nicola Strenzke, ${ }^{1}$ Andreas Neef, ${ }^{3}$ Eckart D. Gundelfinger ${ }^{4}$ Tobias Moser, ${ }^{5}$ and \\ M. Charles Liberman ${ }^{1,2}$ \\ ${ }^{1}$ Eaton-Peabody Laboratory, Massachusetts Eye and Ear Infirmary, Boston, Massachusetts 02114, ${ }^{2}$ Program in Speech and Hearing Bioscience and \\ Technology, Harvard-MIT Division of Health Science and Technology, Cambridge, Massachusetts 02139, ${ }^{3}$ Bernstein Center for Computational \\ Neuroscience, University of Göttingen, D-37073 Göttingen, Germany, ${ }^{4}$ Department of Neurochemistry and Molecular Biology, Leibniz Institute for \\ Neurobiology, 39118 Magdeburg, Germany, and ${ }^{5}$ InnerEarLab, Department of Otolaryngology and Center for Molecular Physiology of the Brain, University \\ of Göttingen, D-37075 Göttingen, Germany
}

Synaptic ribbons, found at the presynaptic membrane of sensory cells in both ear and eye, have been implicated in the vesicle-pool dynamics of synaptic transmission. To elucidate ribbon function, we characterized the response properties of single auditory nerve fibers in mice lacking Bassoon, a scaffolding protein involved in anchoring ribbons to the membrane. In bassoon mutants, immunohistochemistry showed that fewer than $3 \%$ of the hair cells' afferent synapses retained anchored ribbons. Auditory nerve fibers from mutants had normal threshold, dynamic range, and postonset adaptation in response to tone bursts, and they were able to phase lock with normal precision to amplitude-modulated tones. However, spontaneous and sound-evoked discharge rates were reduced, and the reliability of spikes, particularly at stimulus onset, was significantly degraded as shown by an increased variance of first-spike latencies. Modeling based on in vitro studies of normal and mutant hair cells links these findings to reduced release rates at the synapse. The degradation of response reliability in these mutants suggests that the ribbon and/or Bassoon normally facilitate high rates of exocytosis and that its absence significantly compromises the temporal resolving power of the auditory system.

\section{Introduction}

Sensory signals are carried from the cochlea to the brain via $\sim 20,000$ fibers in the auditory nerve (AN), comprising a large population (95\%) of myelinated neurons contacting inner hair cells (IHCs) and a small population (5\%) of unmyelinated fibers contacting outer hair cells (OHCs) (Spoendlin, 1969). The peripheral process of each IHC afferent is unbranched, making synaptic contact with a single IHC via a single terminal swelling (see Fig. 1A). A single ribbon, surrounded by a halo of synaptic vesicles, is anchored to the presynaptic complex opposite the synapse (Spoendlin, 1969, 1972; Liberman, 1980; Spoendlin and Schrott, 1988).

Each ribbon-containing active zone is capable of supporting extremely high rates of exocytosis: a single IHC active zone, with its single synaptic ribbon, can drive the postsynaptic AN fiber at

\footnotetext{
Received Jan. 20, 2010; revised March 23, 2010; accepted April 15, 2010.

This work was supported by the National Institute of Deafness and Other Communication Disorders Grants R01 DC00188 and P30 DC05209 to M.C.L.; a Jack Kent Cooke graduate fellowship to B.N.B.; a fellowship of the German Research Foundation to N.S.; grants of the German Research Foundation (Center for Molecular Physiology of the Brain), the Federal Ministry for Education and Research (BMBF), Bernstein Center for Computational Neuroscience Göttingen), and the European Commission (Eurohear) to T.M.; and Deutsche Forschungsgemeinschaft SFB 779/B9 to E.D.G. A.N. is a Bernstein Fellow of the Bernstein Center for Computational Neuroscience, Göttingen. The guidance of thesis committee members J. J. Guinan, W. F. Sewell, and D. Vetter as well as the technical assistance of L.W. Dodds are gratefully acknowledged. We thank D. Khimich for initial contribution to the project and N. Chapochnikov for discussion and suggestions for data analysis.

Correspondence should be addressed to Bradley N. Buran, Eaton-Peabody Laboratory, Massachusetts Eye and Ear Infirmary, 243 Charles Street, Boston, MA 02114. E-mail: bburan@alum.mit.edu.

DOI:10.1523/JNEUROSCI.0389-10.2010

Copyright $\odot 2010$ the authors $\quad 0270-6474 / 10 / 307587-11 \$ 15.00 / 0$
}

instantaneous rates over 1000 spikes/s at stimulus onset, adapting over a few milliseconds to support sustained rates of up to 400 spikes per second. In addition to encoding stimulus intensity in spike rate, temporal structure is encoded in the fine timing of spikes. Central auditory neurons use this precise timing to resolve temporal features in the signal, such as interaural time differences, on the order of tens of microseconds (Mills, 1958).

In a mouse mutant with partial deletion of Bsn, the gene coding the presynaptic scaffolding protein Bassoon, ribbons are no longer anchored to the active zones (Dick et al., 2003; Khimich et al., 2005; tom Dieck et al., 2005). This model offers a unique opportunity to study the contribution of synaptic ribbons to neurotransmission. In vitro studies of whole-cell capacitance in IHCs from mutant and wild-type mice suggest that the ribbon may facilitate rapid exocytosis by stabilizing a large readily releasable pool of vesicles (Khimich et al., 2005). However, each IHC is contacted by roughly 20 afferent synapses, which have diverse spontaneous and sound-evoked discharge rates. Thus, in vitro hair-cell recordings reflect the summed activity of a heterogeneous population of synapses. To complement the in vitro measurements, we study here the responses of single AN fibers, in vivo, in mutant and wild-type mice. Since each AN fiber receives input from a single active zone on a single IHC, to which a single ribbon is typically anchored (Spoendlin, 1969, 1972; Liberman, 1980; Spoendlin and Schrott, 1988), single-fiber recordings from the AN offer a sensitive metric of the contribution of a single ribbon to synaptic function. 
Many fundamental aspects of AN response were unaffected by disruption of Bassoon and loss of ribbons including tone-burst thresholds, sharpness of tuning, dynamic range, and accuracy of phase locking to amplitude modulations. The salient abnormalities were a striking reduction in spontaneous and sound-evoked discharge rates. Encoding of stimulus onset time was especially degraded because of the reduced reliability of spike generation. We conclude that the ribbon and/or Bassoon are key to stabilizing a large readily releasable pool of synaptic vesicles, which ensures the reliable coding of stimulus onsets necessary for many key aspects of normal auditory processing.

\section{Materials and Methods}

Mice were from a mixed genetic background (C57BL/6 and 129/S6), bred from parents heterozygous for the targeted deletion of exons 4 and 5 of the bassoon gene (Altrock et al., 2003) and genotyped using PCR. Mutant mice and their wild-type littermates were studied at 7-11 weeks of age, before the onset of premature age-related hearing loss that characterizes these strains (Zheng et al., 1999; Hequembourg and Liberman, 2001). Animals with poor cochlear function, as evidenced by high thresholds for distortion product otoacoustic emissions (DPOAEs), were excluded from additional study: these mice comprised $21 \%$ of the population, a ratio that was identical for both genotypes. All procedures were approved by the Institutional Animal Care and Use Committee of the Massachusetts Eye and Ear Infirmary.

The sound system, consisting of dual electrostatic sound sources (Tucker-Davis Technologies; ED-1) and a Knowles Electret microphone coupled to a probe tube, was positioned near the tragus of the external ear canal. The sensitivity of the probe tube microphone was measured between 0.1 and $73 \mathrm{kHz}$ using a calibrated quarter-inch Brüel and Kjær condenser microphone in a coupler.

\section{Auditory brainstem responses and DPOAEs}

For measurement of auditory brainstem responses (ABRs), mice were anesthetized with ketamine $(100 \mathrm{mg} / \mathrm{kg})$ and xylazine $(10 \mathrm{mg} / \mathrm{kg})$, and needle electrodes were inserted at the vertex and pinna with a ground near the tail. ABRs were evoked with $4 \mathrm{~ms}$ tone pips at 40 per second with a $0.4 \mathrm{~ms}$ cosine squared rise-fall envelope and alternating in polarity to remove frequency-following responses. The voltage difference between the pinna and vertex was amplified $(10,000 \times)$, filtered, digitized at 100 $\mathrm{kHz}$, and averaged across 512 presentations. The sound level was raised in $5 \mathrm{~dB}$ steps from $10 \mathrm{~dB}$ below threshold to $80 \mathrm{~dB}$ sound pressure level (SPL). Waveforms were filtered using a zero-phase first-order Butterworth filter with a pass band from 0.2 to $10 \mathrm{kHz}$, and wave amplitudes and latencies were extracted using a semiautomated algorithm. Threshold was defined by visual inspection of stacked waveforms.

DPOAEs at $2 f_{1}-f_{2}$ were recorded in response to primary tones $f_{1}$ and $f_{2}$ with $\mathrm{f}_{2}$ spaced logarithmically at frequencies from 5.6 to $45.2 \mathrm{kHz}$ and the $\mathrm{f}_{2} / \mathrm{f}_{1}$ ratio fixed at 1.2. With $\mathrm{f}_{2}$ set to the level $10 \mathrm{~dB}<\mathrm{f}_{1}$, each frequency pair was swept in $5 \mathrm{~dB}$ steps from below threshold to $80 \mathrm{~dB}$ SPL. The ear-canal sound-pressure waveform was amplified and digitally sampled at $250 \mathrm{kHz}$. Fast Fourier transforms were computed and averaged over five consecutive waveform traces before extraction of the $2 f_{1}-f_{2}$ DPOAE amplitude and surrounding noise floor. Isoresponse contours were interpolated from the $2 \mathrm{f}_{1}-\mathrm{f}_{2}$ amplitude versus sound level function, with threshold defined as the $f_{1}$ level required to produce a DPOAE at $0 \mathrm{~dB}$ SPL.

\section{Single-fiber recordings from the auditory nerve}

In vivo recording from single fibers in the mouse $\mathrm{AN}$ were done as described previously (Taberner and Liberman, 2005).

Surgical approach, inclusion criteria, and preparation stability. Mice were anesthetized with xylazine $(5 \mathrm{mg} / \mathrm{kg})$ and urethane $(1.32 \mathrm{mg} / \mathrm{kg})$ and placed in a sound-proofed, electrically shielded room. Body temperature was maintained at $37^{\circ} \mathrm{C}$. The pinnae were removed, scalp reflected, portions of the lateral interparietal and occipital bone removed, and a partial cerebellar aspiration performed to expose the cochlear nucleus.

Glass electrodes filled with $2 \mathrm{M} \mathrm{KCl}$ and $4 \%$ methyl blue were advanced through the cochlear nucleus into the auditory nerve using a stereotaxic apparatus to angle the track $24^{\circ}$ posterior in the sagittal plane. As defined by Taberner and Liberman (2005), criteria for distinguishing auditory nerve fibers from cochlear nucleus neurons included electrode depth $(>1000 \mu \mathrm{m}$ from brainstem surface) and response properties to tone bursts: primary-like poststimulus time histogram, response latency (mode of the first-spike latency distribution using a $0.1 \mathrm{~ms}$ bin) of $<5 \mathrm{~ms}$, and coefficient of variation for interspike intervals of $>0.5$. At the end of the experiment, the cochlear nucleus was aspirated and the position of the electrode tip within the auditory nerve verified by direct inspection.

DPOAE thresholds were measured after recording from each single fiber to monitor preparation stability: data were included only if the DPOAE threshold near the fiber's characteristic frequency was within 10 $\mathrm{dB}$ of the threshold at the beginning of the experiment.

Stimulus and response measures. Noise bursts (50 ms duration, $80 \mathrm{~dB}$ SPL) were used as a search stimulus while advancing the electrode. After contact with each new fiber, a tuning curve was measured with a computer-based algorithm that tracks the sound pressure required, as a function of frequency, to evoke a response of 10 spikes/s greater than spontaneous rate (SR) (Kiang et al., 1970). Tone bursts (50 ms duration with $2.5 \mathrm{~ms} \cos ^{2}$ rise-fall envelopes, 10 per second) were used for deriving the tuning curve and for all other sound-evoked measurements unless otherwise indicated. Characteristic frequency (CF) was defined from the tuning curve as the frequency with lowest threshold. Spontaneous discharge rate was estimated from samples of spike trains collected in quiet over durations of 10 to $150 \mathrm{~s}$. Poststimulus onset time and interspike-interval histograms, used for distinguishing AN fibers from cochlear nucleus cells, were computed from responses to tone bursts at CF, presented at $30 \mathrm{~dB}$ above threshold.

Rate-level functions were measured with tone bursts at CF. The level was varied in $5 \mathrm{~dB}$ steps, presented in random order, with $20-50$ tone bursts per level. Functions were fitted using a modified version of a model described previously (Taberner and Liberman, 2005). Dynamic range was defined as the difference between the levels at which the driven rate (average rate minus SR) is $10 \%$ and $90 \%$ of the model-fit maximum driven rate.

Synchrony was assessed using transposed tones (Bernstein and Trahiotis, 2002), consisting of a carrier tone at the fiber's CF that was amplitude modulated by a half-wave-rectified sinusoid of $0.125,0.5,0.75$, or 1 $\mathrm{kHz}$. The level of this modulated tone was varied in $5 \mathrm{~dB}$ steps, from below threshold to $80 \mathrm{~dB}$ SPL. The synchronization index (SI) for spike times at each modulation frequency and level was defined as the average of a vector sum, where $t_{i}$ is the time of the $i$ th spike in a train of $n$ spikes, and $\omega$ is the angular frequency of the modulator:

$$
\mathrm{SI}=\frac{\left\|\sum_{i=1}^{n} e^{-j \omega t}\right\|}{n} .
$$

Significance of synchronization was quantified using the Rayleigh statistic, which tests the null hypothesis that the time series is uniform throughout the cycle (Buunen and Rhode, 1978; Mardia and Jupp, 1999): $r=2 n \mathrm{SI}^{2}$. Synchrony data not meeting the criterion of $p<0.001(r \geq$ 13.8) were discarded.

Immunohistochemistry. To count synaptic ribbons in hair cells, anesthetized animals were perfused intracardially with $4 \%$ paraformaldehyde in PBS. Cochleae were decalcified, dissected into half turns, and incubated in 5\% normal horse serum with $0.03 \%$ Triton X-100 in PBS, followed by incubation in primary antibodies (rabbit $\alpha$-calretinin from Millipore and mouse $\alpha$-CtBP2 from Santa Cruz Biotechnology) for $19 \mathrm{~h}$, and secondary antibody (biotinylated donkey $\alpha$-mouse from Jackson ImmunoResearch and Alexa Fluor-488 chicken $\alpha$-rabbit from Invitrogen) for $60 \mathrm{~min}$. Cochlear half turns were wet mounted in Vectashield (Vector Laboratories) and placed on glass slides for examination using a Leica confocal microscope with a $100 \times$ oil-immersion lens. In seven regions spaced approximately a half octave from each other, focal z-series (0.25 $\mu \mathrm{m}$ step size) were obtained. The frequency of each location was estimated using a modified version of the physiological place-frequency map for mice, as recommended by Taberner and Liberman (2005). Amira, a three-dimensional visualization program (Visage Imaging), was 
A

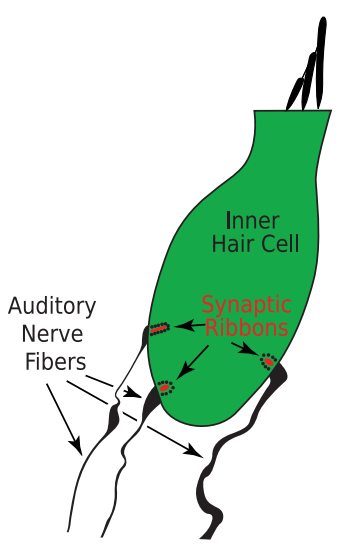

\section{B}
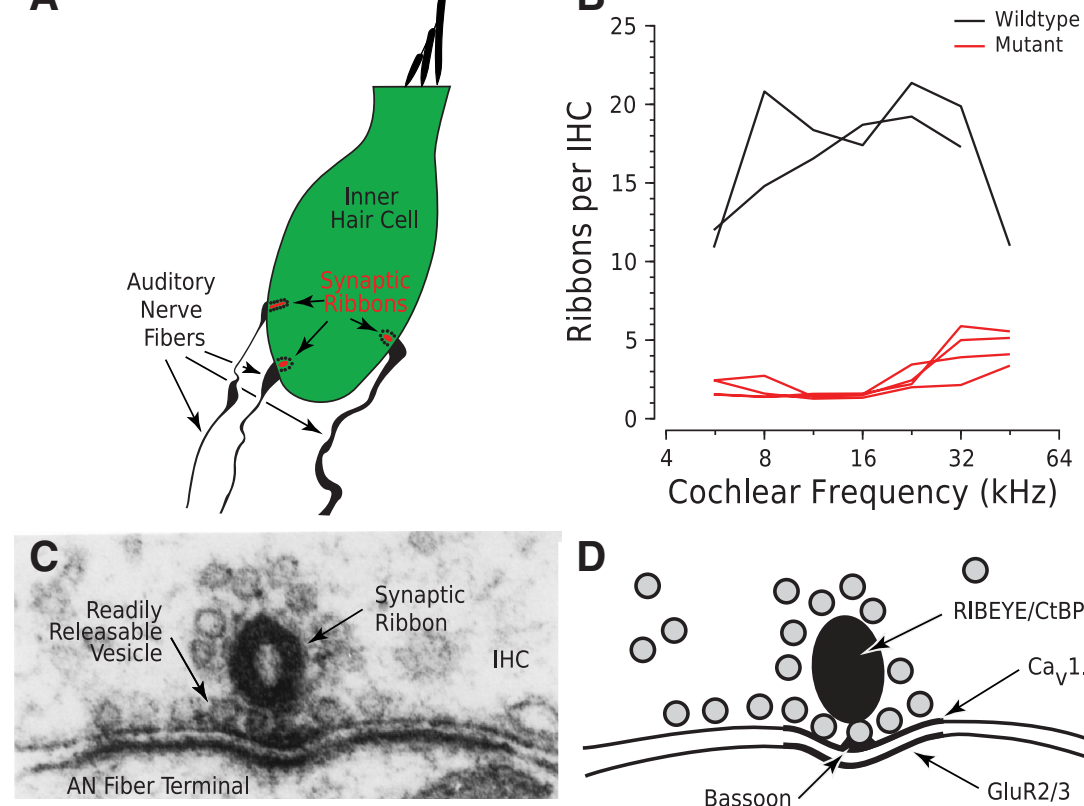

D 0
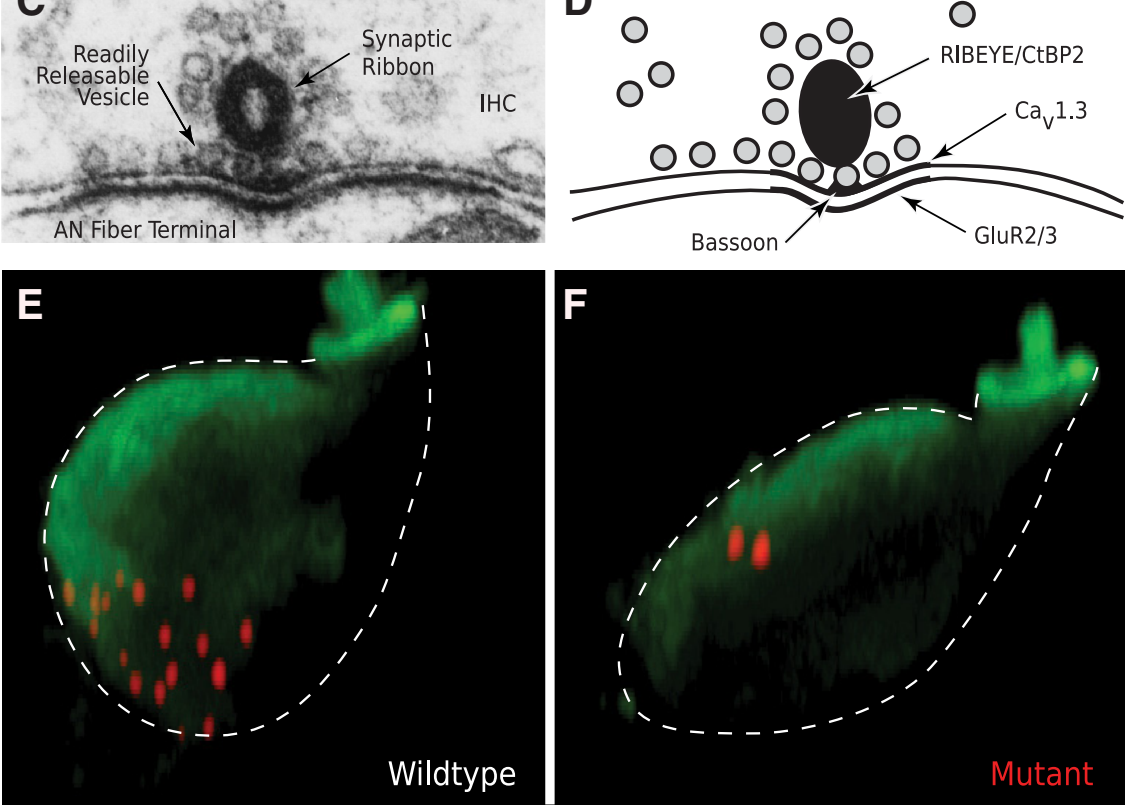

Figure 1. Synaptic ribbons in mutant IHCs are greatly reduced in number. $A$, Schematic of an IHC with a subset (3) of its typical complement $(\sim 20)$ of AN fibers. $B$, Ribbon counts from four mutant and two wild-type ears, based on confocal analysis of cochlear whole mounts such as those in $\boldsymbol{E}$ and $\boldsymbol{F}$. $\boldsymbol{C}, \boldsymbol{D}$, Electron micrograph $(\boldsymbol{C})$ of a hair cell ribbon synapse in cat and an accompanying schematic $(\boldsymbol{D})$ indicating the locations of key synaptic structures. $\boldsymbol{E}, \boldsymbol{F}$, Confocal projections of $\mathrm{IHC}$ from the $16 \mathrm{kHz}$ place in mutant and wild-type mice, immunostained with the synaptic ribbon marker $\alpha$-CtBP2 (red) and an IHC marker, $\alpha$-calretinin (green). Dashed lines indicate outlines of the IHCS.

used to perform three-dimensional Gaussian filtering and transformations. Resulting images were cropped down to the IHC region and passed to Blob3D (University of Texas), a three-dimensional quantitative software, to count the synaptic ribbons.

\section{Results}

\section{Synaptic ribbon counts}

To quantify the number and distribution of synaptic ribbons in Bassoon-deficient ears, sensory epithelia from four mutants and two wild types were immunostained for a ribbon-specific marker, RIBEYE/CtBP2 (Khimich et al., 2005; Meyer et al., 2009), and an IHC label, calretinin (Fig. $1 E, F$ ). In wild types (Fig. $1 B$ ), ribbon counts were consistent with IHC innervation patterns and estimates of synapse numbers from electron microscopic data (Francis et al., 2004; Stamataki et al., 2006), i.e., 12 ribbons/IHC in the basal and apical extremes and 18 ribbons/IHC in midcochlear regions. In mutants, ribbons were reduced in number, ranging from two per IHC in the apex to four per IHC in the base (Fig. $1 B)$. Most of these remaining ribbons were abnormally large (Fig.
$1 F)$, reminiscent of the ribbon fields observed in Bassoon-deficient cone photoreceptor terminals (Dick et al., 2003). Only $10 \%$ were close to the IHC membrane in subnuclear regions, where $\mathrm{AN}$ terminals make contact. Remaining ribbons were floating in the cytosol or in supranuclear regions, consistent with electron microscopic evidence from bassoon mutants (Khimich et al., 2005), indicating that, at most, 1 in $30 \mathrm{AN}$ synapses still had ribbons.

\section{Gross measures of cochlear function}

Two minimally invasive measures of cochlear response, DPOAEs, and ABRs, were used to provide an overview of cochlear dysfunction in the mutants.

DPOAEs are acoustic signals that arise from distortions in the hair cell's mechanoelectric response to two continuous tones. These distortion products, at frequencies not present in the input stimulus, are amplified by OHCs' biological motors and can be detected with a microphone in the ear canal. DPOAEs are unaffected by loss of IHCs or AN fibers (Liberman et al., 1997). Normal DPOAE thresholds in mutants (Fig. $2 \mathrm{~A}$ ) show that many aspects of cochlear function, including mechanoelectric transduction by $\mathrm{OHCs}$, were normal in the absence of synaptic ribbons.

ABRs, evoked by short tone bursts, represent the summed activity of neurons in the ascending auditory pathway and are measured by averaging the evoked electrical response recorded via subcutaneous electrodes. ABR thresholds in mutants were elevated 10 to $15 \mathrm{~dB}$ across most test frequencies (Fig. 2B); the threshold elevation at high frequencies reflects basal-turn $\mathrm{OHC}$ degeneration characteristic of the background strain (Zheng et al., 1999; Hequembourg and Liberman, 2001). The amplitude of the first ABR wave (Fig. 2C), which reflects the summed activity of the AN, was reduced by a factor of 5.4 in mutants (Fig. $2 D$ ), consistent with dysfunction in synaptic transmission. The plateau just before wave 1 (Fig. $2 C$, arrow) is similar in wild types and mutants and may represent the summed receptor potentials of IHCs.

The later ABR waves arise from synchronous neural activity in the auditory brainstem. Wave 2 , for example, is dominated by the response of globular bushy cells in the cochlear nucleus (Melcher and Kiang, 1996), each of which receives afferent input from multiple AN fibers (Spirou et al., 2005). The smaller effect on ABR wave 2 in the mutants suggests a degree of central compensation for the degradation of AN response.

\section{Auditory nerve responses}

To characterize AN response in the absence of synaptic ribbons, recordings were made from $185 \mathrm{AN}$ fibers obtained from 27 wildtype mice and 78 AN fibers from 19 mutant mice. 
Spontaneous rate and

discharge irregularity

Mammalian AN fibers fire spontaneously in the absence of sound (Kiang, 1965); in normal mice, SRs range from near zero to over 180 spikes/s, with a distribution skewed toward low rates (Taberner and Liberman, 2005). Many response properties are normally correlated with SR, e.g., threshold and dynamic range (Sachs and Abbas, 1974; Liberman, 1978; Palmer and Evans, 1980; Schalk and Sachs, 1980; Taberner and Liberman, 2005).

In mutant fibers, SRs were significantly lower than normal (Fig. $3 A, B$ ), never exceeding 80 spikes/s in mutants, compared with a maximum of 183 spikes/s in wild types. The mean SR across all fibers sampled was reduced by a factor of 4.0.

Spontaneous discharge in AN fibers is highly irregular, with statistics consistent with a Poisson process. Interspike intervals show an exponential distribution with a dead time caused by the absolute refractory period (Young and Barta, 1986; Li and Young, 1993) (but see Heil et al., 2007). This fundamental irregularity of AN response was not altered by loss of ribbons, as seen by the similarity of interspike interval histograms from wild-type and mutant fibers of similar SR (Fig. 3C). To systematically assess differences in response regularity, we split AN fibers into groups of similar SRs (within two spikes per second), discarded fibers with significant $(p \leq 0.05)$ fluctuations in rate as described by Heil et al. (2007), and performed a statistical test on each group: out of 10 groups containing at least one wild-type and one mutant fiber, none had interspike interval distributions that differed significantly $(p \leq 0.05)$ as assessed by the two-sample KolmogorovSmirnov test.

\section{Tuning and threshold}

AN fibers have a high degree of frequency selectivity. This frequency response is typically measured as a tuning curve (supplemental Fig. S1 $B$, inset, available at www.jneurosci.org as supplemental material), reflecting the tone level required to evoke a response that is 10 spikes/s greater than SR. The sensitive tip of the tuning curve defines the $\mathrm{CF}$, which reflects the fiber's origin along the mechanically tuned cochlear spiral: high frequencies originate in the base of the cochlea, whereas lower frequencies are from progressively more apical locations (Liberman, 1982). Since this exquisite frequency selectivity requires the electromechanical feedback of OHCs (Liberman et al., 2002), which amplifies cochlear vibration, it is not surprising that the distribution of
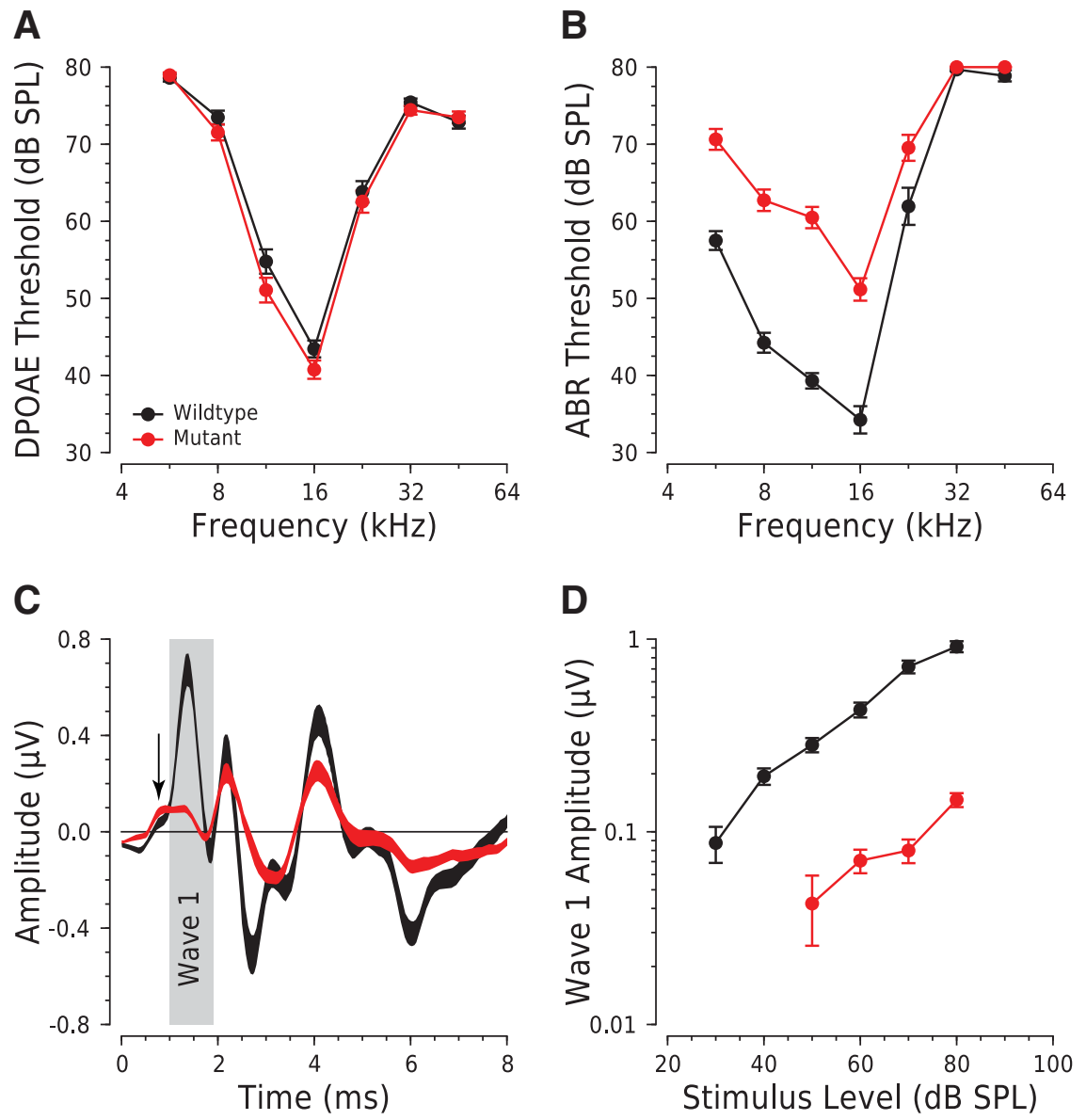

Figure 2. $\quad \boldsymbol{A}-\boldsymbol{D}, 0$ toacoustic emissions are normal in mutants $(\boldsymbol{A})$, whereas $A B R$ sare reduced $(\boldsymbol{B}, \boldsymbol{C}, \boldsymbol{D})$, consistent with impaired synaptic transmission. $A$, Mean DPOAE thresholds for mutant versus wild-type ears ( $n=70$ of each genotype). $B$, Mean ABR thresholds for mutants $(n=53)$ versus wild types $(n=50)$. C, Mean ABR waveforms from responses to $16 \mathrm{kHz}$ tone pips at $80 \mathrm{~dB}$ SPL from mutants $(n=53)$ versus wild types $(n=50)$. $D$, Mean amplitude versus level functions for $A B R$ wave 1 from wild types $(n=48)$ versus mutants $(n=57)$ from responses to $16 \mathrm{kHz}$ pips. The color key in $\boldsymbol{A}$ applies to all panels. Error bars $(\boldsymbol{A}, \boldsymbol{B}, \boldsymbol{D})$ or trace thickness $(\boldsymbol{C})$ indicate \pm SEM.
A

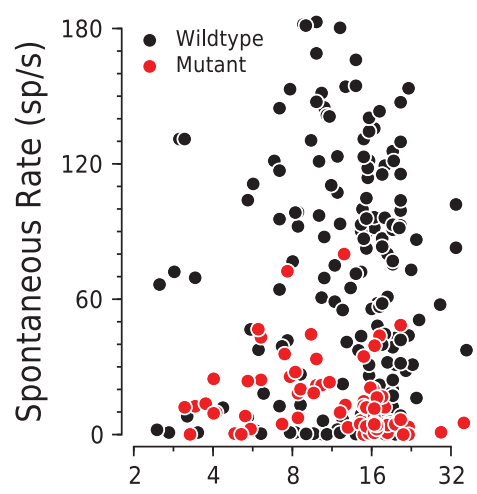

Char. Frequency $(\mathrm{kHz})$
B

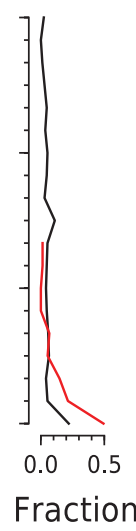

C

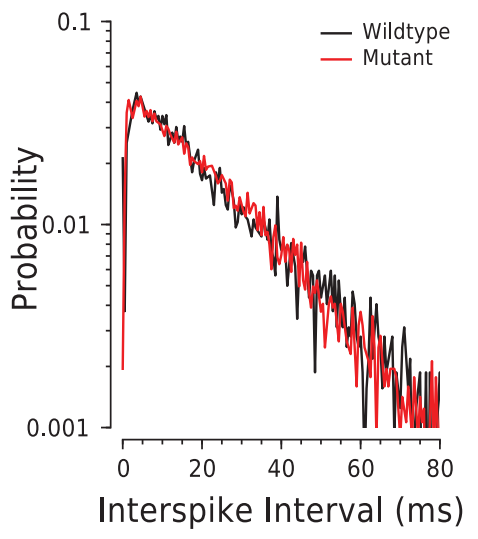

Figure 3. $A-C$, SR is reduced in mutant AN fibers $(A, B)$; however, spike discharge remains irregular (C). $A, S R$ as a function of characteristic frequency for all AN fibers sampled. $\boldsymbol{B}$, Frequency distribution showing the fraction of fibers with SRs in different ranges (bin width, 10 spikes/s). $C$, Interspike interval histograms of spontaneous activity from all fibers with SR between 40 and 50 spikes per second: these histograms are normalized by the total spike count to reflect an estimate of the probability density function (bin width, $0.5 \mathrm{~ms}$ ).

thresholds (supplemental Fig. S1A, available at www.jneurosci.org as supplemental material) and tuning (supplemental Fig. $\mathrm{S} 1 B$, available at www.jneurosci.org as supplemental material) are normal in mutant AN fibers, given the normal DPOAE thresh- 
A

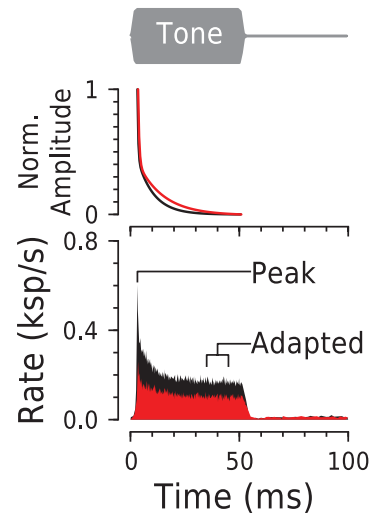

B
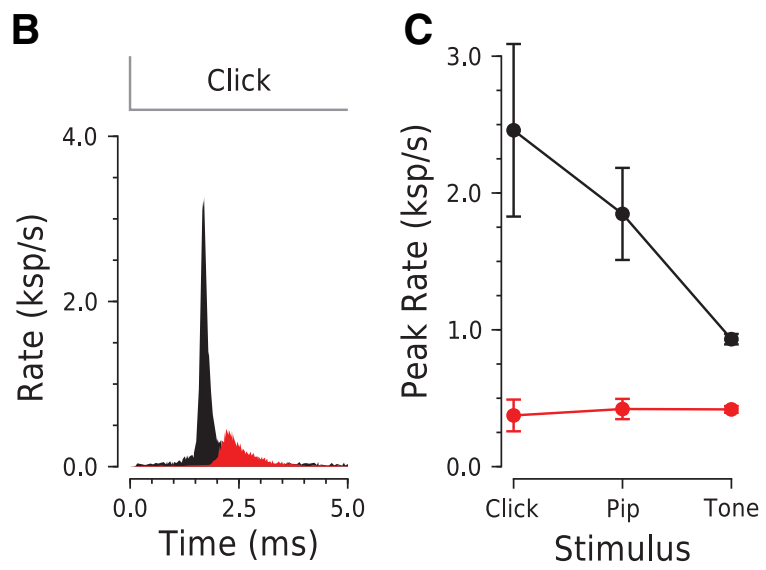

D

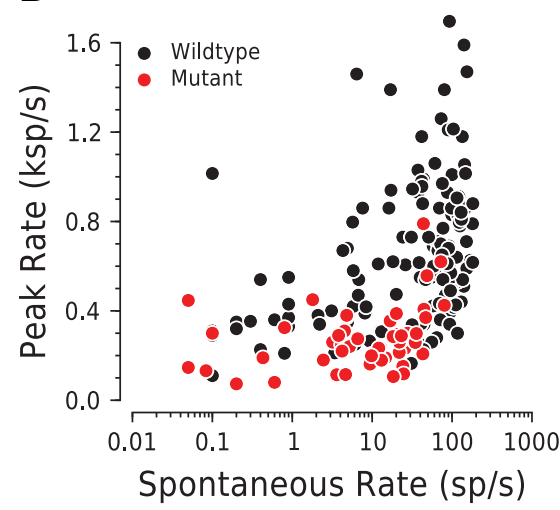

E

Schalk and Sachs, 1980). In mouse AN fibers, discharge rate typically saturates within $20 \mathrm{~dB}$ of threshold (Taberner and Liberman, 2005) (supplemental Fig. S2 A, available at www.jneurosci.org as supplemental material). Since IHC receptor potentials show a larger dynamic range (Russell and Sellick, 1978; Palmer and Russell, 1986), hard saturation in AN fibers is thought to arise in synaptic transmission. When matched for SR, there is no difference in dynamic range between mutant and wild-type fibers, indicating that the presynaptic machinery that controls graded synaptic drive remains intact in the absence of synaptic ribbons (supplemental Fig. S2 B, available at www.jneurosci.org as supplemental material).

AN fibers normally respond to tone bursts with a spike rate that declines exponentially from a maximum at stimulus onset (i.e., peak rate) to an adapted rate (Fig. 4A). For $50 \mathrm{~ms}$ tone bursts, this adaptation can be described as the sum of a rapid and a slow time constant (Westerman and Smith, 1984) of approximately 0.65 and $10 \mathrm{~ms}$, respectively. Since a similar decrease is not observed in the IHC receptor potential (Russell and Sellick, 1978; Palmer and Russell, 1986), and the reduction in calcium current (Hudspeth and Lewis, 1988; Moser and Beutner, 2000; Yang et al., 2006; Cui et al., 2007) and postsynaptic AMPA receptor desensitization (Goutman and Glowatzki, 2007) are minimal, adaptation is thought to arise mainly in synaptic transmission, e.g., via exhaustion of the readily releasable pool of synaptic vesicles (Furukawa and Matsuura, 1978; Moser and Beutner, 2000; Goutman and Glowatzki, 2007).

In mutant ears, $\mathrm{AN}$ response showed

olds (Fig. 2 A). To assess whether mean single-fiber threshold was unchanged, fibers were grouped by CF into half-octave bins and an independent two-sample, two-tailed Student's $t$ test computed on each bin. For CFs $<16 \mathrm{kHz}$, where the data are unaffected by the high-frequency pathophysiology in this background strain (Zheng et al., 1999; Hequembourg and Liberman, 2001), there were no significant threshold differences between the genotypes.

In normal ears, $\mathrm{AN}$ threshold is inversely correlated with SR: high-SR fibers (SR of $>10$ spikes/s) are, on average, 10-20 dB more sensitive than low-SR fibers $(<10$ spikes/s) of similar CF (Liberman, 1978). Such correlations are weak when data are pooled across many animals, as in the present study. Although mean SR was reduced in the mutants, a weak correlation between SR and threshold remained (Spearman rank-order correlation coefficient, $r=-0.29$, two-sided $p=0.05$ in mutants; $r=-0.17$, $p=0.10$ in wild types; data not shown).

Sound-evoked discharge rates, adaptation, and dynamic range When stimulated with tones, a normal AN fiber produces a graded response: mean spike rate increases with increasing level, but only over a limited range of levels (Sachs and Abbas, 1974; clear postonset adaptation (Fig. $4 \mathrm{~A}$ ) in response to saturating $\mathrm{CF}$ tone bursts. Adaptation was difficult to quantify for individual fibers because sampling times were insufficient to produce poststimulus time histograms of the requisite smoothness; thus, average histograms were generated by pooling data from fibers of similar SRs. Time constants of mutant fibers were similar to those of wild types when matched for SR (e.g., for fibers with an SR between 10 and 80 spikes/s, the rapid time constant was 0.64 vs $0.81 \mathrm{~ms}$, and the slow time constant was $9.3 \mathrm{vs} 11.4 \mathrm{~ms}$ ). However, the amplitudes of the rapid and slow components were reduced by factors of 3.8 and 1.9, respectively. Like wild-type, mutant fibers were able to maintain adapted discharge rates for stimulus durations of at least $5 \mathrm{~min}$ (data not shown).

Sound-evoked discharge rates in single fibers, both peak (Fig. $4 D$ ) and adapted (Fig. $4 E$ ), were significantly reduced (independent two-sample, two-tailed Student's $t$ test; $p<0.001)$ in mutants by factors of 2.5 and 1.8, respectively, when averaged across all fibers. Peak rates are normally correlated with SRs (Fig. 4D). However, even when matched for SR, the peak rates in mutants were reduced (Fig. $4 D$ ). This reduction was more pronounced when the stimulus rise time was more abrupt. For example, clicks 
(Fig. $4 B, C$ ), with a nominally instantaneous onset produced a larger difference in peak rates (factor of 6.5) than tone bursts shaped with a $2.5 \mathrm{~ms}$ rise time (Fig. $4 A, C)$. Correspondingly, the tone pips used to measure ABRs (with an intermediate rise time of $0.4 \mathrm{~ms}$ ) produced an intermediate peak-rate reduction (factor of 4.4) (Fig. 4C), which is close to the 5.4fold reduction seen in mutant $\mathrm{ABR}$ amplitudes (Fig. 2C,D); this large reduction in peak rate likely explains the striking elevation in ABR threshold despite normal single-fiber thresholds in mutants.

First-spike latency and

spike-time reliability

Accurate coding of stimulus onsets is critical for many auditory tasks such as localizing sounds in space, requiring precise timing and reliable occurrence of first spikes in AN fibers. Failures to produce a spike, as well as variance in the timing of the first spike relative to stimulus onset, are detrimental when convergence of simultaneous AN inputs onto higher-level neurons is required. The distribution of first-spike latencies, as illustrated by dot raster plots of spike times in response to repeated tone bursts (Fig. $5 A$ ), demonstrates why mutant fibers fail to achieve high peak rates: for many stimulus presentations, the mutant fiber fails to produce a spike in response to stimulus onset (Fig. 5B).

One way to capture the difference in the distributions of first-spike latencies is to compute the distribution variance (Fig.

$5 C)$. The variance tends to increase with decreasing SR in wild types. When matched for SR, mutant fibers show significantly higher variance by a factor of 4.9 , on average. Thus, the spike times are significantly less reliable, even in response to tone bursts at a level high enough to saturate the mean discharge rate.

\section{Phase locking and spike-time accuracy}

In response to periodic, amplitude-modulated stimuli, AN fibers tend to fire at a preferred phase of the stimulus cycle (Kiang, 1965; Rose et al., 1967). This phase locking, or synchrony, is essential for key aspects of binaural hearing. For example, small differences in the relative timing of sound between the two ears are the dominant cue for localizing low-frequency sounds (Wightman and Kistler, 1992; Macpherson and Middlebrooks, 2002). Precise timing of IHC exocytosis is required to maintain the fidelity of synaptic transmission required to encode these interaural differences.

Low-frequency pure tones are typically used to assess AN phase locking (Kiang, 1965); however, spike synchronization decreases as tone frequency approaches $4 \mathrm{kHz}$ because IHC membrane capacitance filters out high-frequency components in the receptor potential (Palmer and Russell, 1986). Since few mouse AN fibers are sensitive to frequencies below $4 \mathrm{kHz}$ (Johnson, 1980; Taberner and Liberman, 2005), we used an amplitudemodulated high-frequency carrier known as a transposed tone (Bernstein and Trahiotis, 2002), in which the modulation enve- lope is a half-wave-rectified, low-frequency sinusoid, and the carrier is set to the fiber's CF (Fig. 6A, top). Because half-wave rectification is inherent in cochlear mechanoelectric transduction, the resulting temporal modulation of IHC receptor potential is similar to the pattern that would be produced by a low-frequency sinusoid (Palmer and Russell, 1986; Dreyer and Delgutte, 2006).

In response to transposed tones, phase locking in mutant $\mathrm{AN}$ fibers was as precise as, or more precise than, in wild types (Fig. 6 ), as can be seen in either dot raster plots (Fig. 6A), period histograms (Fig. 6C), or interspike interval histograms (Fig. $6 B$ ). Spikes in both mutant and wild-type fibers clearly lock to the low-frequency amplitude modulation. The SI is a classic metric for assessing the strength of this phase locking (Goldberg and Brown, 1969). The synchronization index varies between 1 (all spikes occur at the same phase of the stimulus cycle) and 0 (spikes occur randomly throughout the cycle). On average, the synchronization indices were greater in mutant than wild-type fibers (Fig. $6 D)$; however, this difference arises from the reductions in SR: spontaneous spikes occur at random times and therefore degrade this measure of synchronization. When matched for SR, the maximum synchrony was comparable in wild-type and mutant fibers across all modulation frequencies tested (data not shown).

The ensemble interspike interval histograms (Fig. 6B) highlight the important difference between spike precision and spike reliability. Wild-type fibers tended to produce a precisely timed 
A
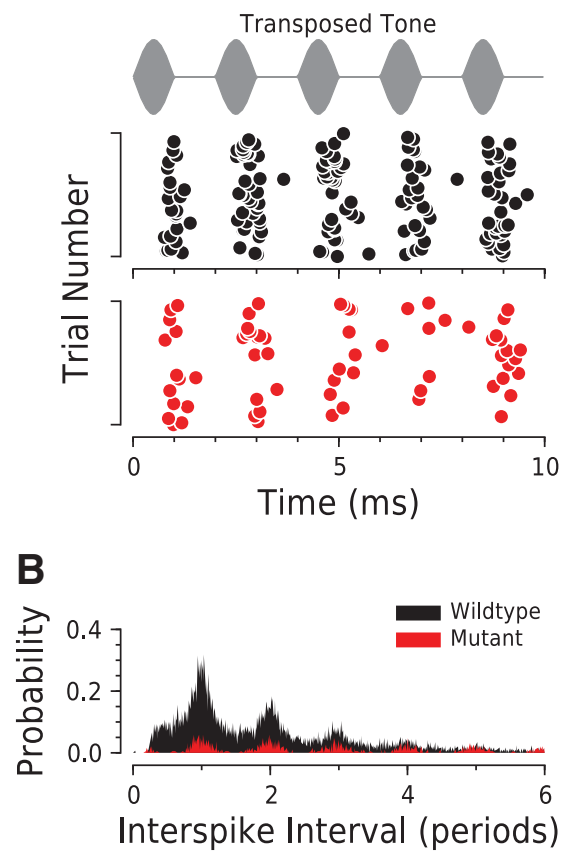

\section{C}

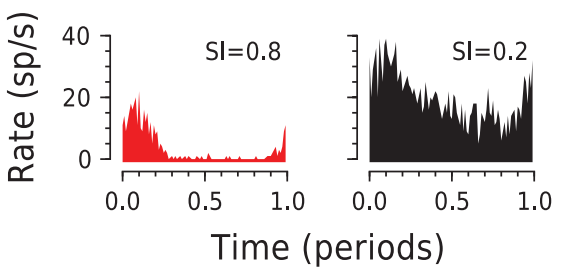

D

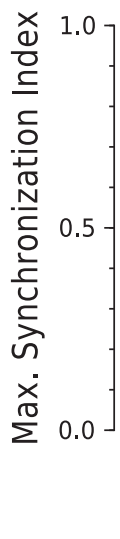

available for analysis increased, estimates converged toward $0.61 \mathrm{~ms}$ (supplemental Fig. S3B, available at www.jneurosci.org as supplemental material). Although the mean absolute refractory period for mutants is lower than the wild type, values were similar when matched for rate. Estimates for the time constant of the relative refractory period ranged from $2.5 \mathrm{~ms}$ at the lowest driven rates (50 spikes/s) to a minimum of $0.45 \mathrm{~ms}$ at the highest rates (350 spikes/s); however, no remarkable difference was observed between wildtype and mutant fibers when matched for rate (supplemental Fig. S3C, available at www.jneurosci.org as supplemental material).

\section{Modeling AN response from inferred vesicle release rates}

The reliability of spike onset times in normal AN fibers is mediated by coordinated release from a pool of readily releasable vesicles maintained by the synaptic ribbon (Khimich et al., 2005; Moser et al., 2006; Goutman and Glowatzki, 2007; Wittig and Parsons, 2008). To test whether the kinetics of presynaptic exocytosis could explain the spike activity observed in wild-type and mutant AN fibers, we modeled synaptic transmission (Fig. 7) using vesicle release rates estimated from depolarization-evoked membrane capacitance changes in IHCs from wild-type and mutant mice (Khimich et al., 2005).

The increase in plasma membrane capacitance, $\Delta C_{m}(\Delta t)$, measured after a depolarizing stimulus of duration $\Delta t$, reflects the surface area added by vesicles

spike on almost every stimulus cycle: the peak at spike intervals of one period is the highest. Spike discharge in mutant fibers was as precisely locked with the stimulus phase; however, mutant fibers were less reliable in producing a spike on each cycle of the amplitude modulation: spike intervals of $1,2,3$, or 4 periods were equally probable.

\section{Absolute and relative refractory periods}

Reduction in spontaneous and sound-evoked activity could arise from a prolonged refractory period. Although refractoriness is a property of the postsynaptic membrane, it is conceivably a downstream effect of this synaptic disruption. To rule out this possibility, refractory periods were estimated from spike trains obtained under conditions of constant synaptic drive ( $\mathrm{Li}$ and Young, 1993) by computing spike probability as a function of the time since the last spike (supplemental Fig. S3A, available at www.jneurosci.org as supplemental material), i.e., the hazard function. The absolute refractory period is the smallest interspike interval, and the relative refractory period is the time constant for the portion of the hazard function over which probability increases to asymptote. To ensure adequate spike counts, we used data derived from the adapted portion of responses to tone bursts (Fig. 4A).

At the lowest rates, estimates of the absolute refractory period ranged from 0.6 to $10 \mathrm{~ms}$. However, as the number of spikes exocytosed during the stimulus. Dividing $\Delta C_{m}(\Delta t)$ by the average capacitance per vesicle, $c_{\mathrm{sv}}=44.5 \mathrm{aF}$ (Neef et al., 2007), and the number of synapses per IHC, num $m_{\text {syn }}=11.5$ (Khimich et al., 2005), returns the cumulative number of vesicles released with rate $R(t)$ during $\Delta t$.

$$
\int_{0}^{\Delta t} R(t) d t=\frac{\Delta C_{m}(\Delta t)}{C_{\mathrm{sv}} \cdot \text { num }_{\mathrm{syn}}} .
$$

Release rate was estimated by fitting an exponential function to the first 2 to $10 \mathrm{~ms}$ of the cumulative release, with the data weighted in the fitting algorithm according their standard errors, and accounting for a $1 \mathrm{~ms}$ delay in exocytosis (Beutner et al., 2001; Brandt et al., 2005; Goutman and Glowatzki, 2007). The initial release rate, $R_{0}$, is the derivative of the fit function evaluated at the onset of the exocytic response (supplemental Table S1, available at www.jneurosci.org as supplemental material), and the release rate after the first $10 \mathrm{~ms}$ is approximated by a linear fit between 10 and 20 ms. Mutant IHCs showed a $\sim 2.5$-fold reduction in initial release rate but a comparable release time constant (supplemental Table S1, available at www.jneurosci.org as supplemental material), consistent with a reduced size of the readily releasable pool, but unaltered 
vesicular release probability. The difference in steady-state release was smaller (supplementalTableS1, availableatwww. jneurosci.org as supplemental material), suggesting that vesicle resupply at mutant synapses is less affected by loss of the ribbon and/or Bassoon.

To compare these in vitro IHC recordings to the AN data, we devised a model in which the readily releasable pool $(B)$ consists of vesicles that occupy a fixed number of slots $\left(N_{\text {slots }}\right)$. Vesicles are released from these slots with a rate constant, $k_{\mathrm{re}^{-}}$ lease, relating release rate to the fill level of the readily releasable pool:

$$
R(t)=B(t) \cdot k_{\text {release }} .
$$

Empty slots are refilled from a reserve pool with a rate constant, $k_{\text {refill }}$, yielding the following differential equation and its solution:

$$
\begin{aligned}
B= & -k_{\text {release }} \cdot B(t)+k_{\text {refill }} \\
B(t)= & N_{\text {slots }} \cdot\left(\frac{\left.k_{\text {refill }}-B(t)\right),}{k_{\text {release }}+k_{\text {refill }}}\right. \\
& \left.+\frac{k_{\text {release }}}{k_{\text {release }}+k_{\text {refill }}} e^{-t\left(k_{\text {release }}+k_{\text {refill }}\right)}\right) .
\end{aligned}
$$

In this framework, spike-rate adaptation reflects declining release rate resulting from depletion of the readily releasable pool and its rate-limiting resupply.

To compare vesicle release dynamics with AN responses to tone bursts (Figs. 4, $5)$, a time-dependent release probability, $k_{\text {release }}(t)$, was used to mimic the $2.5 \mathrm{~ms}$ onset envelope of the tone burst. The dynamic range of an AN synapse was set to $20 \mathrm{~dB}$, with $k_{\text {release }}(t)$ growing linearly with stimulus intensity within that range. The release rates resulting from Equations 3 and 4 were then used to drive an inhomogeneous Poisson process to estimate first-release-event latencies: as expected, the distribution for mutant synapses was broader than that for wild types (Fig. $7 B$ ).

To determine how increased variance of first-release times would degrade onset responses in AN fibers, we extended the model to spike generation (Fig. $7 C, D$ ). Spike times were generated using the presynaptic release rate to drive an inhomogeneous Poisson process with refractoriness (Berry and Meister, 1998); i.e., the release rate was convolved with the refractoriness function. After downscaling release rates (factor of 0.137) (Fig. $7 A$, dashed lines), the modeled spike rate resembles AN response and captures the essential differences in onset rate and postonset adaptation between mutants and wild types (Fig. 7C). Furthermore, the modeled first-spike latency distributions (Fig. 7D) capture the increased variance in mutant AN responses (model standard deviations were 7.4 vs $3.2 \mathrm{~ms}$, compared with observed values of 5.1 vs $2.3 \mathrm{~ms}$ for mutants vs wild types, respectively). The downscaling of release rates required to fit the AN data may
B

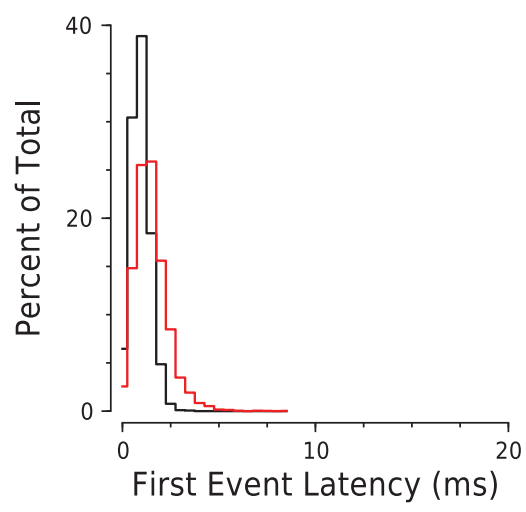

D

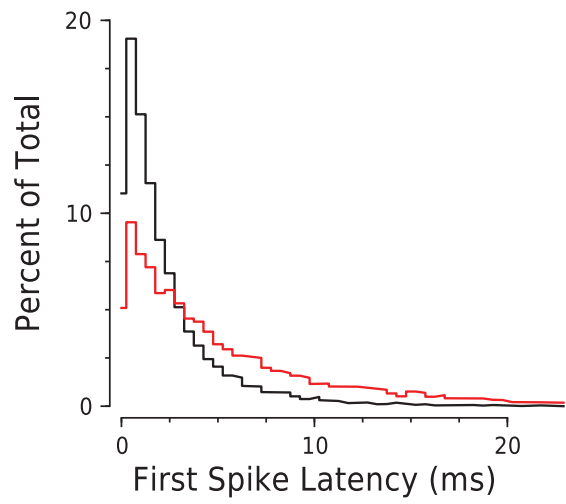

Figure 7. Reduced presynaptic release rate can account for degraded reliability of spike onset coding in mutant fibers. $\boldsymbol{A}$, Mean vesicle release rates for wild-type and mutant synapses, derived from IHC capacitance recordings at 8 weeks. Dashed lines (inferred 作 IHCS. C, Poststimulus time histograms of simulated and measured spike rates in response to tone bursts. Simulated rates were obtained from convolving the "effective" rate of excitatory input with the refractoriness function. Since capacitance measures were apical turn. The simulated histograms were shifted in time so that the peak rates matched those of the recorded data. $D$, Simulated first-spike latency distributions show the experimentally observed broadening in mutant fibers.

reflect differences between in vivo and in vitro conditions such as temperature and extracellular calcium concentration as well as the maximization of evoked calcium currents used in vitro (Khimich et al., 2005).

\section{Discussion}

\section{Mechanisms underlying the degradation of onset coding}

Each AN fiber receives synaptic input from a single IHC via a single presynaptic active zone to which a single synaptic ribbon is anchored (Liberman, 1980) (Fig. 1A). A small number of synaptic vesicles $(<250)$ are clustered around each ribbon (MerchanPerez and Liberman, 1996) (Fig. 1C). Each IHC ribbon synapse normally supports instantaneous AN discharge rates at a stimulus onset of over 1000 spikes/s as well as sustained sound-evoked rates up to 400 spikes/s while mediating the synchronization of spike times with stimulus periodicity at frequencies up to $4 \mathrm{kHz}$ (Johnson, 1980); stimulus intensity is conveyed via discharge rate modulation, whereas timing cues are encoded in the interspike intervals. Data from the present study suggest that the primary function of the synaptic ribbon and/or Bassoon is to maintain a large readily releasable pool, enabling high rates of exocytosis and 
thereby allowing the faithful encoding of stimulus onset time in the auditory periphery.

AN responses in the absence of synaptic ribbons were normal in many respects: spike intervals retained their normal irregularity (Fig. 3), the dynamic range of the synapse was unchanged (Fig. S2, available at www.jneurosci.org as supplemental material), adaptation of spike rate after stimulus onset was unaffected (Fig. 4), and spike synchronization to amplitude modulation was intact (Fig. 6). Precise spike synchronization requires both fast kinetics of voltage-gated calcium channels $\left(\mathrm{Ca}_{\mathrm{v}} 1.3\right)$ in IHCs (Zidanic and Fuchs, 1995; Neef et al., 2009) to allow calcium concentration to track rapid fluctuations in IHC receptor potential and a population of release-ready vesicles docked close to these calcium channels. The normal AN synchronization to amplitude-modulated tones in mutant animals (Fig. 6) suggests that both requirements are still met in the absence of the synaptic ribbon.

The key response anomalies in the absence of synaptic ribbons and Bassoon were a prominent reduction in discharge rates, both spontaneous (Fig. 3) and sound evoked (Fig. 4), and a loss of spike reliability at stimulus onset, seen as increased variance of the first-spike latencies (Fig. 5). These abnormalities are well explained by a decrease in the size of the release-ready vesicle pool. Whole-cell capacitance measures from IHCs in vitro reveal two components to depolarization-induced exocytosis. The rapid, transient component likely reflects exocytosis of a finite readily releasable pool of vesicles and underlies the rapid postonset adaption of AN response to tone bursts (Moser and Beutner, 2000). The slower, sustained component probably reflects vesicle replenishment at the active zone (Schnee et al., 2005; Li et al., 2009; Meyer et al., 2009). In IHCs from bassoon mutants, rapid and sustained exocytosis were reduced by factors of 2.5 and 1.5, respectively (supplemental Table S1, available at www.jneurosci.org as supplemental material). However, mutants also showed a 1.5fold decrease in calcium current, possibly attributable to a reduction of calcium channel numbers at the active zone (Khimich et al., 2005). This reduced calcium current may explain the reduction in sustained exocytosis and, thus, the 1.6-fold reduction of sustained rates in mutant AN fibers. However, rapid exocytosis in mutant IHCs was low, even when compared to wild-type IHCs with calcium currents artificially reduced by a factor of 1.5 (Khimich et al., 2005). Similarly, AN onset rates were reduced in mutants 2.5 - to 6.5 -fold, depending on the rapidity of stimulus onset. This data is consistent with a key role for the ribbon and/or Bassoon in rapid exocytosis, as a reduction in rapid exocytosis decreases the probability of spike generation at stimulus onset.

In this study, we used computational modeling to predict in vivo AN response from the rates of synaptic exocytosis inferred from depolarization-evoked changes in IHC membrane capacitance (Fig. 7). Using a model of transmitter release and spike generation, we matched the observed poststimulus time histograms of wild-type AN fibers by downscaling synaptic drive, estimated from in vitro conditions, by a factor of $\sim 8$ (Fig. 7 ). Applying the same scaling to the exocytotic rates of mutant IHCs matched the observed AN peak rate in mutants. Thus, reducing initial release rates from mutant synapses can explain the observed degradation of sound-onset coding and the increased variance of first-spike latencies in the AN (see also Wittig and Parsons, 2008). The closeness of fit for AN peak rates in mutants versus wild types indicate that the depolarization-evoked capacitance changes on which they are based reflect mainly synaptic exocytosis. In contrast, the mismatch between modeled and observed values for sustained rate may reflect increased extrasynaptic exocytosis in mutant IHCs.
The similar dependence of spontaneous and sound-evoked discharge rates on the electrical driving force across the apical hair cell membrane suggests similar mechanisms (Sewell, 1984a,b). Given the steady-state nature of SR measures, it is surprising that the observed (fourfold) SR reduction in mutant AN fibers was larger than that for sustained sound-evoked rates. Because of the lack of spontaneous activity under in vitro conditions, we are unable to draw any conclusions regarding the nature of SR from our model.

Genetic manipulation of Bassoon, one of the largest structural proteins at the active zone (tom Dieck et al., 1998; Richter et al., 1999; Fenster et al., 2000), could conceivably disrupt synaptic transmission through mechanisms unrelated to loss of the synaptic ribbon. Indeed, loss of Bassoon has been reported to "silence" some hippocampal glutamatergic synapses (Altrock et al., 2003). However, if the striking degradation of AN discharge rate, and onset reliability, is attributable to the loss of Bassoon, per se, rather than the absence of the ribbon, this elaborate synaptic structure must be superfluous since all other AN response properties in mutants were indistinguishable from normal.

\section{Auditory performance: predicted effects on high-level processing}

Although both spike synchronization to amplitude modulation (Rose et al., 1967; Johnson, 1980) and first-spike variance in response to stimulus onsets (Mainen and Sejnowski, 1995) (for review, see Tiesinga et al., 2008) are used to quantify "temporal precision" in the auditory system, these performance measures have different underlying requirements. Reproducibility of firstspike latency requires both reliability and precision of spiking, whereas synchrony (as it is typically measured) requires only precision. AN fibers lacking ribbons were unreliable in that spikes were not elicited by every cycle of the amplitude modulation, even at very low modulation rates. However, they were precise in that, when spikes occurred, they encoded the temporal envelope with high fidelity. Thus, the synchronization index was not degraded by ribbon loss. On the other hand, the first-spike latency metric was degraded, since decreased reliability means that, on many trials, the first spike was not evoked until long after stimulus onset (Fig. 5).

High onset rates are critical to temporal precision in the auditory periphery (Moser et al., 2006). The decrease in soundevoked discharge rates and degradation of $\mathrm{AN}$ onset response in the absence of the synaptic ribbon should have profound consequences for auditory central processing. Since all mammalian IHCs, including humans', have ribbon synapses (Liberman et al., 1990; Nadol, 1990), and since mouse AN responses are similar to other mammals' (Kiang, 1965; Evans, 1972; Taberner and Liberman, 2005), the present results are presumably applicable to human hearing.

Rapid onsets are pervasive in the auditory environment, with many natural sounds and vocalizations characterized by sharp transients and rapid amplitude modulations (Lesica and Grothe, 2008; Elliott and Theunissen, 2009). The ability to resolve temporal structure is key for a number of auditory tasks including sound localization (Wightman and Kistler, 1992; Macpherson and Middlebrooks, 2002) and speech intelligibility (Elliott and Theunissen, 2009). Indeed, certain speech sounds can be discriminated by envelope rise time alone (Cutting and Rosner, 1974), which is encoded in the AN by differences in onset rate (Delgutte, 1980).

Many central auditory circuits rely on the precise coincidence of spikes from converging ascending inputs. For example, in the cochlear nucleus, the first stage of central auditory processing, 
octopus cells are designed to respond only to stimulus onset by virtue of their short membrane time constant, which limits the temporal summation of postsynaptic potentials from numerous small AN terminals on their dendrites (Golding et al., 1995). Indeed, a large fraction of these terminals must be active within a restricted time window to produce a postsynaptic spike. The reduced reliability of onset response in bassoon mutants (Fig. 5) reduces the number of synchronous inputs at each onset, likely eliminating octopus cell responses to many rapid-onset stimuli. Onset responses may also be important in processing acoustic cues in reverberant environments (Wallach et al., 1949; Devore et al., 2009) (for review, see Litovsky et al., 1999), and the degradation of onset responses likely decreases the effectiveness of this key neural circuitry.

The neuronal coincidence detectors in the superior olivary complex, a tertiary stage of auditory processing, are also well characterized. These cells compare binaural inputs to compute the location of sounds in space by assessing interaural time differences that arise for stimuli in the azimuthal plane and are sensitive to differences in interaural times as small as $10 \mu$ s (Goldberg and Brown, 1969; Yin and Chan, 1990; Spitzer and Semple, 1995; Batra et al., 1997). The decreased reliability of onset responses in AN fibers lacking synaptic ribbons and/or bassoon may significantly compromise the ability to rapidly localize sounds using this coincidence-detection circuitry.

\section{References}

Altrock WD, tom Dieck S, Sokolov M, Meyer AC, Sigler A, Brakebusch C, Fässler R, Richter K, Boeckers TM, Potschka H, Brandt C, Löscher W, Grimberg D, Dresbach T, Hempelmann A, Hassan H, Balschun D, Frey JU, Brandstätter JH, Garner CC, et al. (2003) Functional inactivation of a fraction of excitatory synapses in mice deficient for the active zone protein bassoon. Neuron 37:787-800.

Batra R, Kuwada S, Fitzpatrick DC (1997) Sensitivity to interaural temporal disparities of low- and high-frequency neurons in the superior olivary complex. I. Heterogeneity of responses. J Neurophysiol 78:1222-1236.

Bernstein LR, Trahiotis C (2002) Enhancing sensitivity to interaural delays at high frequencies by using "transposed stimuli." J Acoust Soc Am 112:1026-1036.

Berry MJ, Meister M (1998) Refractoriness and neural precision. J Neurosci 18:2200-2211.

Beutner D, Voets T, Neher E, Moser T (2001) Calcium dependence of exocytosis and endocytosis at the cochlear inner hair cell afferent synapse. Neuron 29:681-690.

Brandt A, Khimich D, Moser T (2005) Few CaV1.3 channels regulate the exocytosis of a synaptic vesicle at the hair cell ribbon synapse. J Neurosci 25:11577-11585.

Buunen TJ, Rhode WS (1978) Response of fibers in the cat's auditory nerve to the cubic difference tone. J Acoust Soc Am 64:772-781.

Cui G, Meyer AC, Calin-Jageman I, Neef J, Haeseleer F, Moser T, Lee A (2007) $\mathrm{Ca}^{2+}$-binding proteins tune $\mathrm{Ca}^{2+}$-feedback to Cav1.3 channels in mouse auditory hair cells. J Physiol 585:791-803.

Cutting J, Rosner B (1974) Categories and boundaries in speech and music. Percept Psychophys 16:564-570.

Delgutte B (1980) Representation of speech-like sounds in the discharge patterns of auditory-nerve fibers. J Acoust Soc Am 68:843-857.

Devore S, Ihlefeld A, Hancock K, Shinn-Cunningham B, Delgutte B (2009) Accurate sound localization in reverberant environments is mediated by robust encoding of spatial cues in the auditory midbrain. Neuron 62:123-134

Dick O, tom Dieck S, Altrock WD, Ammermuller J, Weiler R, Garner CC, Gundelfinger ED, Brandstatter JH (2003) The presynaptic active zone protein bassoon is essential for photoreceptor ribbon synapse formation in the retina. Neuron 37:775-786.

Dreyer A, Delgutte B (2006) Phase locking of auditory-nerve fibers to the envelopes of high-frequency sounds: implications for sound localization. J Neurophysiol 96:2327-2341.

Elliott TM, Theunissen FE (2009) The modulation transfer function for speech intelligibility. PLoS Comput Biol 5:e1000302.
Evans EF (1972) The frequency response and other properties of single fibres in the guinea-pig cochlear nerve. J Physiol 226:263-287.

Fenster SD, Chung WJ, Zhai R, Cases-Langhoff C, Voss B, Garner AM, Kaempf U, Kindler S, Gundelfinger ED, Garner CC (2000) Piccolo, a presynaptic zinc finger protein structurally related to bassoon. Neuron 25:203-214.

Francis HW, Rivas A, Lehar M, Ryugo DK (2004) Two types of afferent terminals innervate cochlear inner hair cells in C57BL/6J mice. Brain Research 1016:182-194.

Furukawa T, Matsuura S (1978) Adaptive rundown of excitatory postsynaptic potentials at synapses between hair cells and eight nerve fibres in the goldfish. J Physiol 276:193-209.

Goldberg JM, Brown PB (1969) Response of binaural neurons of dog superior olivary complex to dichotic tonal stimuli: some physiological mechanisms of sound localization. J Neurophysiol 32:613-636.

Golding NL, Robertson D, Oertel D (1995) Recordings from slices indicate that octopus cells of the cochlear nucleus detect coincident firing of auditory nerve fibers with temporal precision. J Neurosci 15:3138-3153.

Goutman JD, Glowatzki E (2007) Time course and calcium dependence of transmitter release at a single ribbon synapse. Proc Natl Acad Sci U S A 104:16341-16346.

Heil P, Neubauer H, Irvine DR, Brown M (2007) Spontaneous activity of auditory-nerve fibers: insights into stochastic processes at ribbon synapses. J Neurosci 27:8457-8474.

Hequembourg S, Liberman MC (2001) Spiral ligament pathology: a major aspect of age-related cochlear degeneration in C57BL/6 mice. J Assoc Res Otolaryngol 2:118-129.

Hudspeth AJ, Lewis RS (1988) Kinetic analysis of voltage- and iondependent conductances in saccular hair cells of the bull-frog, Rana catesbeiana. J Physiol (Lond) 400:237-274.

Johnson DH (1980) The relationship between spike rate and synchrony in responses of auditory-nerve fibers to single tones. J Acoust Soc Am 68:1115-1122.

Khimich D, Nouvian R, Pujol R, tom Dieck S, Egner A, Gundelfinger ED, Moser T (2005) Hair cell synaptic ribbons are essential for synchronous auditory signalling. Nature 434:889-894.

Kiang NY (1965) Discharge patterns of single fibers in the cat's auditory nerve. Cambridge, MA: MIT Press.

Kiang NY, Moxon EC, Levine RA (1970) Auditory-nerve activity in cats with normal and abnormal cochleas. In: Sensorineural hearing loss, pp 241-273 (Wolstenholme GE, Knight J, eds). London: Churchill.

Lesica NA, Grothe B (2008) Efficient temporal processing of naturalistic sounds. PLoS One 3:e1655.

Li G, Keen E, Andor-Ardó D, Hudspeth AJ, von Gersdorff H (2009) The unitary event underlying multiquantal EPSCs at a hair cell's ribbon synapse. J Neurosci 29:7558-7568.

Li J, Young ED (1993) Discharge-rate dependence of refractory behavior of cat auditory-nerve fibers. Hear Res 69:151-162.

Liberman MC (1978) Auditory-nerve response from cats raised in a lownoise chamber. J Acoust Soc Am 63:442-455.

Liberman MC (1980) Morphological differences among radial afferent fibers in the cat cochlea: An electron-microscopic study of serial sections. Hear Res 3:45-63.

Liberman MC (1982) The cochlear frequency map for the cat: labeling auditory-nerve fibers of known characteristic frequency. J Acoust Soc Am 72:1441-1449.

Liberman MC, Dodds LW, Pierce S (1990) Afferent and efferent innervation of the cat cochlea: Quantitative analysis with light and electron microscopy. J Comp Neurol 301:443-460.

Liberman MC, Chesney C, Kujawa SG (1997) Effects of selective inner hair cell loss on DPOAE and CAP in carboplatin-treated chinchillas. Aud Neurosci 3:255-268.

Liberman MC, Gao J, He DZZ, Wu X, Jia S, Zuo J (2002) Prestin is required for electromotility of the outer hair cell and for the cochlear amplifier. Nature 419:300-304.

Litovsky RY, Colburn HS, Yost WA, Guzman SJ (1999) The precedence effect. J Acoust Soc Am 106:1633-1654.

Macpherson EA, Middlebrooks JC (2002) Listener weighting of cues for lateral angle: the duplex theory of sound localization revisited. J Acoust Soc Am 111:2219-2236.

Mainen ZF, Sejnowski TJ (1995) Reliability of spike timing in neocortical neurons. Science 268:1503-1506. 
Mardia KV, Jupp PE (1999) Directional statistics. New York: Wiley.

Melcher JR, Kiang NY (1996) Generators of the brainstem auditory evoked potential in cat III: identified cell populations. Hear Res 93:52-71.

Merchan-Perez A, Liberman MC (1996) Ultrastructural differences among afferent synapses on cochlear hair cells: Correlations with spontaneous discharge rate. J Comp Neurol 371:208-221.

Meyer AC, Frank T, Khimich D, Hoch G, Riedel D, Chapochnikov NM, Yarin YM, Harke B, Hell SW, Egner A, Moser T (2009) Tuning of synapse number, structure and function in the cochlea. Nat Neurosci 12:444-453.

Mills AW (1958) On the minimum audible angle. J Acoust Soc Am 30:237-246.

Moser T, Beutner D (2000) Kinetics of exocytosis and endocytosis at the cochlear inner hair cell afferent synapse of the mouse. Proc Natl Acad Sci U S A 97:883-888.

Moser T, Neef A, Khimich D (2006) Mechanisms underlying the temporal precision of sound coding at the inner hair cell ribbon synapse. J Physiol 576:55-62.

Nadol JB (1990) Synaptic morphology of inner and outer hair cells of the human organ of Corti. J of Electron Microscopy Technique 15:187-196.

Neef A, Khimich D, Pirih P, Riedel D, Wolf F, Moser T (2007) Probing the Mechanism of Exocytosis at the Hair Cell Ribbon Synapse. J Neurosci 27:12933-12944.

Neef J, Gehrt A, Bulankina AV, Meyer AC, Riedel D, Gregg RG, Strenzke N, Moser T (2009) The Ca2 + channel subunit beta2 regulates $\mathrm{Ca} 2+$ channel abundance and function in inner hair cells and is required for hearing. J Neurosci 29:10730-10740.

Palmer AR, Evans EF (1980) Cochlear fibre rate-intensity functions: no evidence for basilar membrane nonlinearities. Hea Res 2:319-326.

Palmer AR, Russell IJ (1986) Phase-locking in the cochlear nerve of the guinea-pig and its relation to the receptor potential of inner hair-cells. Hear Res 24:1-15.

Richter K, Langnaese K, Kreutz MR, Olias G, Zhai R, Scheich H, Garner CC, Gundelfinger ED (1999) Presynaptic cytomatrix protein Bassoon is localized at both excitatory and inhibitory synapses of rat brain. J Comp Neurol 408:437-448.

Rose JE, Brugge JF, Anderson DJ, Hind JE (1967) Phase-locked response to low-frequency tones in single auditory nerve fibers of the squirrel monkey. J Neurophysiol 30:769-793.

Russell IJ, Sellick PM (1978) Intracellular studies of hair cells in the mammalian cochlea. J Physiol 284:261-290.

Sachs MB, Abbas PJ (1974) Rate versus level functions for auditory-nerve fibers in cats: tone-burst stimuli. J Acoust Soc Am 56:1835-1847.

Schalk TB, Sachs MB (1980) Nonlinearities in auditory-nerve fiber responses to bandlimited noise. J Acoust Soc Am 67:903-913.

Schnee M, Lawton D, Furness D, Benke T, Ricci A (2005) Auditory hair cell-afferent fiber synapses are specialized to operate at their best frequencies. Neuron 47:243-254

Sewell WF (1984a) The relation between the endocochlear potential and spontaneous activity in auditory nerve fibres of the cat. J Physiol 347:685-696

Sewell WF (1984b) Furosemide selectively reduces one component in ratelevel functions from auditory-nerve fibers. Hear Res 15:69-72.
Spirou G, Rager J, Manis P (2005) Convergence of auditory-nerve fiber projections onto globular bushy cells. Neuroscience 136:843-863.

Spitzer MW, Semple MN (1995) Neurons sensitive to interaural phase disparity in gerbil superior olive: diverse monaural and temporal response properties. J Neurophysiol 73:1668-1690.

Spoendlin H (1969) Innervation patterns in the organ of corti of the cat. Acta Otolaryngol 67:239-254.

Spoendlin H (1972) Innervation densities of the cochlea. Acta Otolaryngol 73:235-248.

Spoendlin H, Schrott A (1988) The spiral ganglion and the innervation of the human organ of Corti. Acta Otolaryngol 105:403-410.

Stamataki S, Francis HW, Lehar M, May BJ, Ryugo DK (2006) Synaptic alterations at inner hair cells precede spiral ganglion cell loss in aging C57BL/6J mice. Hear Res 221:104-118.

Taberner AM, Liberman MC (2005) Response properties of single auditory nerve fibers in the mouse. J Neurophysiol 93:557-569.

Tiesinga P, Fellous J, Sejnowski TJ (2008) Regulation of spike timing in visual cortical circuits. Nat Rev Neurosci 9:97-107.

tom Dieck S, Sanmarti-Vila L, Langnaese K, Richter K, Kindler S, Soyke A Wex H, Smalla K, Kampf U, Franzer J, Stumm M, Garner CC, Gundelfinger ED (1998) Bassoon, a novel zinc-finger CAG/glutamine-repeat protein selectively localized at the active zone of presynaptic nerve terminals. J Cell Biol 142:499-509.

tom Dieck S, Altrock WD, Kessels MM, Qualmann B, Regus H, Brauner D, Fejtova A, Bracko O, Gundelfinger ED, Brandstatter JH (2005) Molecular dissection of the photoreceptor ribbon synapse: physical interaction of Bassoon and RIBEYE is essential for the assembly of the ribbon complex. J Cell Biol 168:825-836.

Wallach H, Newman E, Rosenzweig M (1949) The precedence effect in sound localization. Am J Psychol 62:315-336.

Westerman LA, Smith RL (1984) Rapid and short-term adaptation in auditory nerve responses. Hear Res 15:249-260.

Wightman FL, Kistler DJ (1992) The dominant role of low-frequency interaural time differences in sound localization. J Acoust Soc Am 91:16481661.

Wittig JH, Parsons TD (2008) Synaptic ribbon enables temporal precision of hair cell afferent synapse by increasing the number of readily releasable vesicles: a modeling study. J Neurophysiol 100:1724-1739.

Yang PS, Alseikhan BA, Hiel H, Grant L, Mori MX, Yang W, Fuchs PA, Yue DT (2006) Switching of $\mathrm{Ca}^{2+}$-dependent inactivation of CaV1.3 channels by calcium binding proteins of auditory hair cells. J Neurosci 26:10677-10689.

Yin TC, Chan JC (1990) Interaural time sensitivity in medial superior olive of cat. J Neurophysiol 64:465-488.

Young ED, Barta PE (1986) Rate responses of auditory nerve fibers to tones in noise near masked threshold. J Acoust Soc Am 79:426-442.

Zheng QY, Johnson KR, Erway LC (1999) Assessment of hearing in 80 inbred strains of mice by ABR threshold analyses. Hear Res 130:94-107.

Zidanic M, Fuchs PA (1995) Kinetic analysis of barium currents in chick cochlear hair cells. Biophys J 68:1323-1336. 